method of selecting references on specific subjects. Regional Medlars centres are being set up in the United States and abroad, and are being provided with copies of Medlars citation files on magnetic tapes made at the National Library of Medicine. The British Medlars service, which is run jointly by the National Lending Library for Science and Technology at Boston Spa and the Computer Laboratory of the University of Newcastle upon Tyne, has been in operation for some time. It can supply references on specific subjects, and it is about to offer recurring searches for individuals or organizations needing a "current awareness" service.

From 1880 to 1955 the National Library of Medicine, then the Surgeon General's Library, was responsible for the production of 61 volumes of the Index-Catalogue. Though it proved impossible to continue this monumental work, in January 1966 the Library was able to begin publication of the National Library of Medicine Current Catalog, which, appearing biweekly, lists monographic accessions and gives quarterly and annual cumulations. The catalogue includes author, title, and series entries, and in addition the cumulations have a subject arrangement. Each author entry contains the subject and additional citations needed for descriptive cataloguing. The price of each item in dollars is given wherever possible. This catalogue is a major advance in bibliographical reporting, since it provides an up-to-date record of the monographic and serial publications being collected by the largest medical library in the world. ${ }^{2}$

The latest annual report of the National Library of Medicine $^{3}$ provides further evidence of its contributions towards the advancement of medicine, and underlines the essential role of medical libraries. Among other matters it reports that the Library assisted Congress and the Administration when they were considering the Medical Library Assistance Act, 1955. This measure, which was passed by the legislators in October 1965, provides for funds totalling $\$ 105 \mathrm{~m}$. to be made available over a period of five years for a wide variety of purposes. The latter include the building or expansion of medical libraries, the purchase of books and equipment, training medical librarians, and research in the field. ${ }^{4}$

This bold and imaginative programme will ensure considerable improvements in American medical libraries. It should be copied on a smaller scale in Britain, where at present some libraries are not able to provide the best service that is possible. ${ }^{5}$

\section{Hirschsprung's Disease in Infancy}

Since the first description ${ }^{1}$ by Harold Hirschsprung of the condition which has come to bear his name there has been controversy about its management. ${ }^{2}$ The condition is due to absence or abnormality of the parasympathetic ganglion cells in the colon, usually in the recto-sigmoid region, though the entire length may be affected. The aganglionic segment remains unexpanded and the proximal colon becomes distended and hypertrophied. "Congenital megacolon" is not a good term, as colonic distension is rarely present at birth. Hirschsprung's disease is one of the commoner and more lethal forms of intestinal obstruction in the newborn. It is for this reason that the condition is relatively rare in adult life, and it is probable that many babies die untreated (and undiagnosed) in early life. While many people still associate Hirschsprung's disease with abdominal distension and constipation, diarrhoea is not uncommon (from overflow, stercoral ulceration, or necrotizing enterocolitis) and may be a sign of the utmost gravity.

In 1948 O. Swenson and A. H. Bill ${ }^{3}$ published an authoritative account of the pathology of congenital megacolon and described an abdomino-perineal pull-through operation which preserved the rectal sphincter. This operation, with various modifications, was adopted in surgical paediatric centres throughout the world, with dramatic improvement in results. Unfortunately the procedure was associated with an unacceptable morbidity and mortality in the hands of many European surgeons, and this led them to adopt alternative operations. B. Duhamel ${ }^{45}$ excluded but did not resect the aganglionic rectum and others have further modified this procedure. F. Soave $^{6-8}$ utilized a procedure first described by $M . M$. Ravitch, ${ }^{9}$ and after denuding the rectum of its mucosa performed a non-suture anocolic anastomosis by pulling the ganglionic colon out beyond the anal orifice. All three procedures are widely practised, but, though the operative mortality is now low, many deaths still occur in infants before they have been treated by definitive surgery.

Now Swenson and his colleagues ${ }^{10}$ have called for another reappraisal of thought on neonatal Hirschsprung's disease. They suggest " an aggressive combined attack by paediatrician, radiologist, pathologist, and surgeon to diagnose and prepare the sick infant as early as possible for colostomy or definitive surgery." Swenson and his co-workers claim that by careful selection and painstaking operative technique definitive surgery can be carried out with greater success in infants than in older children. They describe 50 children with "congenital megacolon" treated in the Children's Memorial Hospital, Chicago, in the past six years. Twelve infants with an average weight of $5.7 \mathrm{~kg}$. were treated by a definitive pull-through procedure, and another 26 by colostomy and resection, with no deaths or complications. Two patients were awaiting resection. Of the ten deaths nine were in patients less than 5 weeks old: three died before surgical intervention. Though this overall mortality of only $20 \%$ reflects great credit on Swenson and his team, his plea for such an aggressive attack must be considered in the light of all its implications.

Many surgeons in Europe find the diagnosis of Hirschsprung's disease in early infancy less easy than Swenson suggests. The clinical, radiological, and histological pictures may be confusing. The more widespread recognition of pseudo (para) Hirschsprung's disease ${ }^{11}$ adds to the confusion. New radiological techniques have been introduced, such as the use of barium by mouth with an accelerator instead of the traditional barium enema; and these, together with the use of histochemical methods, may lead to refinements in diagnosis which permit a better assessment of the prognosis and the best treatment for the patients. A confirmed aganglionosis confined to a short segment of bowel may be

\footnotetext{
'Hirschsprung, H., fb. Kinderheilk., 1887, 27, 1.

- Swenson, O., and Bill, A. H., jun., Surgery, 1948, 24, 212

- Duhamel, B., Presse méd., 1956, 64, 2249.

- Duhamel, B., Presse méd., 1956, 64

- Soave, F., Osped. Ital.-Chir., 1963, 8, 285.

Arch. Dis. Childh., 1964, 39, 116 Brit. \%. Surg., 1966, 53, 1023.

- Ravitch, M. M., and Sabiston, D. C., jun., Surg. Gynec. Obstet., 1947. 84, 1095.

10 Shim, W. K. T., and Swenson, O., Pediatrics, 1966, 38, 185.

1 Arch. Dis. Childh., 1966, 41, 143.

2 Bentley, J. F. R., ibid., 1966, 41, 144.
} 
symptomatically cured by posterior excisional ano-rectal myotomy ${ }^{12}-\mathrm{a}$ much less hazardous procedure than a definitive procedure.

Paediatric surgeons will agree with Shim and Swenson on the advantages of these patients going to a large children's hospital with specialized departments of radiology, pathology, and biochemistry. In the field of neonatal emergency surgery it is essential that a team of highly skilled surgeons and pathologists must be available round the clock, as newborn victims of conditions such as Hirschsprung's disease usually present as an emergency.

\section{Tangled Bill}

As the Abortion Bill becomes increasingly tangled up in the House of Commons standing committee opinion is growing outside that a fresh start ought somehow to be made. The legislative approach to this important social problem has often seemed-at least to medical men and women-to be at once impetuous and haphazard. The Times has suggested withdrawal of the Bill and a thorough inquiry into the facts here and abroad. ${ }^{1}$ Other critics believe a Royal Commission would make the issues plainer, though their opponents must command some sympathy in doubting whether a Royal Commission is the right instrument for the task.

Like the community at large the medical profession is not unanimous on how best to resolve the complex and emotionally charged problems, though it is worth reiterating that some leading gynaecologists doubt whether there is any need, either for the patient or for her doctor, to have the present case law embodied in statutory form. ${ }^{2}$ If it is to be, then one outstanding principle to follow is that doctors should be required to exercise judgement only on matters within their professional competence. What are often called social grounds for abortion-though perhaps sometimes more properly described as domestic-can come into the doctor's consideration of the case only in so far as they affect his patient's life or health. ${ }^{34}$ A doctor cannot take medical decisions, especially of such gravity as termination of pregnancy, for reasons which he is not professionally equipped to weigh up. The sponsors of the present Bill have shown themselves to be sensitive to this argument but disinclined to accept it in its entirety. The result now is to replace various proposed amendments defining the principal grounds for abortion by the following clauses:

(i) that the continuance of the pregnancy would involve risk to the life or injury to the physical or mental health of the pregnant woman or the future well-being of herself and/or the child or her other children;

(ii) in determining whether or not there is such risk of injury to health or well-being account may be taken of the patient's total environment actual or reasonably foreseeable.

If these words were to become law they would be the explicit guide to which doctors would have to turn in doubtful cases, of which there may be many. And lawyers too would be required to devote to them the same minute attention they have so often given, for example, to the McNaughton Rules. Yet the clauses need no more than a first reading for their ambiguities and obscurities to be obvious. How can a doctor

\footnotetext{
1 The Times, 7 February 1967

Brit. med. F., 1965, 1, 1009.

s Ibid., 1966, 2, 1607.

- Ibid., 1966, 2, 1649

I Ibid., 1967, 1, 512.
}

estimate the future well-being of a mother as something separate from the risk to life or health of continuing the pregnancy? And, in the context of these clauses, what of the future well-being of "the child or her other children"? Again, what sort of difference is intended in the second clause between " health" and "well-being"? For all this to be the upshot of what our Parliamentary Correspondent called "three mornings of controversy and seven votes" 5 must cause anxiety about the direction this legislation is taking. Is familiar case law to be replaced by a statute full of traps ?

\section{Management of Acute Poisoning}

The incidence of acute poisoning in Great Britain has increased considerably in recent years. ${ }^{1}$ Thus probably about 36,000 patients will be admitted to hospital this year with acute poisoning, and over 6,000 people will die of it. ${ }^{2}$ In some hospitals these patients form as much as $10 \%$ of the acute medical cases, and large numbers of persons consult their family doctors about exposure to a potentially poisonous substance which proves to be relatively harmless. In general practice episodes of this kind are twice as frequent in children as in adults and amount to several thousands per year. $^{3}$ Of the admissions to hospital for poisoning, on the other hand, not more than $27 \%$ are children. ${ }^{4}$ About twothirds of the patients admitted to hospital are suffering from the effects of depressant drugs-which are classified as "analgesics and soporifics," and which include hypnotics, sedatives, tranquillizers, and, above all, barbiturates. This is not unduly surprising when it is realized that 30 million prescriptions for depressant drugs are dispensed annually in England and Wales alone.

To ensure that the facilities for treatment were put to best use the Central Health Services Council appointed a committee under the chairmanship of Professor Hedley Atkins ${ }^{5}$ "to consider arrangements for the emergency treatment of cases of acute poisoning in hospitals." In 1962 this committee recommended that one general hospital in each area should be designated as the preferred receiving centre for patients with acute poisoning and that it should be called the district centre. Hospitals with special facilities such as intermittent haemodialysis-though this has only a strictly limited value in the treatment of poisoning ${ }^{6}$ - might serve as regional poisoning treatment centres. The report made no proposal to establish intensive-care units exclusively for cases of poisoning, but it recommended that "the district centre should be in the charge of a physician especially interested in cases of poisoning who should be designated to deal with such

1 Report on Hospital In-patients Enquiry, 1956-57, 1959, 1960, 1961. Published 1961, 1961, 1962, and 1963 respectively. H.M.S.O. London.

${ }^{2}$ Registrar General's Statistical Review for England and Wales, 1964 1966. H.M.S.O., London.

- Goulding, R., and Watkin, R. R., Mth. Bull. Minist. Hlth Lab. Sero. 1965, 24, 26.

Report on Hospital In-patients Enquiry, 1961, Table 4, 1963. H.M.S.O., London.

- Atkins, H. J. B., Emergency Treatment in Hospital of Cases of Acute Poisoning, Central Health Services Council, 1962. H.M.S.O. London.

- Graham, J. D. P., Practitioner, 1966, 197, 528

Clemmesen, C., Dan. med. Bull., 1963, 10, 97

- Matthew, H., and Lawson, A. A. H., Quart. F. Med., 1966, 35, 539.

- Unpublished information.

10 Hospital Memorandum. Emergency Treatment in Hospital of Cases of Acute Poisoning (No. 12) 13: Hospital Memorandum Poisons Information Service (No. 63) 75. Ministry of Health, London. 